\title{
Technical review and evaluation of the economics of water desalination: Current and future challenges for better water supply sustainability
}

\author{
Noreddine Ghaffour, Thomas M. Missimer, Gary L. Amy \\ Water Desalination and Reuse Center, King Abdullah University of Science and Technology (KAUST), \\ KAUST Campus, P.O. Box 4700, ZC 23955-6900, Thuwal, Saudi Arabia \\ Email: noreddine.ghaffour@kaust.edu.sa, Tel.+966-28082180
}

\begin{abstract}
Desalination capacity has rapidly increased in the last decade because of the increase in water demand and a significant reduction in desalination cost as a result of significant technological advances, especially in the reverse osmosis process. The cost of desalinated seawater has fallen below US\$0.50/ $\mathrm{m}^{3}$ for a large scale seawater reverse osmosis plant at a specific location and conditions while in other locations the cost is $50 \%$ higher $\left(\mathrm{US} \$ 1.00 / \mathrm{m}^{3}\right.$ ) for a similar facility. In addition to capital and operating costs, other parameters such as local incentives or subsidies may also contribute to the large difference in desalted water cost between regions and facilities. Plant suppliers and consultants have their own cost calculation methodologies, but they are confidential and provide water costs with different accuracies. The few existing costing methodologies and software packages such as WTCost $\complement$ and DEEP provide an estimated cost with different accuracies and their applications are limited to specific conditions. Most of the available cost estimation tools are of the black box type, which provide few details concerning the parameters and methodologies applied for local conditions. Many desalination plants built recently have greater desalinated water delivery costs caused by special circumstances, such as plant remediation or upgrades, local variation in energy costs, and site-specific issues in raw materials costs (e.g., tariffs and transportation). Therefore, the availability of a more transparent and unique methodology for estimating the cost will help in selecting an appropriate desalination technology suitable for specific locations with
\end{abstract}


consideration of all the parameters influencing the cost. A techno- economic evaluation and review of the costing aspects and the main parameters influencing the total water cost produced by different desalination technologies are herein presented in detail. Some recent developments, such as the increase of unit capacity, improvements in process design and materials, and the use of hybrid systems have contributed to cost reduction as well as reduction in energy consumption. The development of new and emerging low-energy desalination technologies, such as adsorption desalination, will have an impact on cost variation estimation in the future.

Keywords: Desalination cost; Desalination technologies development; Energy consumption; Economics; Costing methodologies.

\section{Introduction}

Many water-stressed or arid regions or countries are augmenting their water supply with desalinated water to meet the increased water demand caused by growth triggered by increased population, industrial expansion, tourism, and agriculture development. In some areas, desalination is no longer a marginal or supplemental water resource in some countries. Qatar and Kuwait rely $100 \%$ on desalinated water for domestic and industrial supplies [1].

Presently, the total global desalination capacity is around 66.4 million $\mathrm{m}^{3} /$ day and it is expected to reach about 100 million $\mathrm{m}^{3} / \mathrm{d}$ by 2015 [2]. Of the global desalted water, $63.7 \%$ of the total capacity is produced by membrane processes and $34.2 \%$ by thermal processes (Figure 1-left). The desalination source water is split with about $58.9 \%$ from seawater and $21.2 \%$ from brackish groundwater sources, and the remaining percentage from surface water and saline wastewater [2]. These figures are constantly changing because the desalination market is growing very rapidly. The growth of desalination capacity 
worldwide is shown in Figure 1-right. The growth rate is currently about 55\% per year [2], a truly stunning figure.

Figure 1: Installed (left) and forecast (right) desalination capacity by technology (as of first quarter of 2012) [2].

The increase of desalination capacity is caused primarily by increases in water demand but also by the significant reduction in desalination cost as a result of significant technological advances that result in making desalinated water cost-competitive with other water sources. In some specific areas, desalination is now been able to successfully compete with conventional water resources and water transfers for potable water supply (e.g., construction of dams and reservoirs or canal transfers) [3].

A thorough review of technical developments and cost trends of the most commercial desalination processes, including multistage flash distillation (MSF), multi effect distillation (MED), vapor compression (VC), reverse osmosis (RO) and electrodialysis (ED) was presented in earlier studies by Reddy and Ghaffour [4], Wade [5] and Miller [6]. Greenlee et al. [7] also conducted a brief review of the key parameters on seawater reverse osmosis (SWRO) and brackish water reverse osmosis (BWRO), respectively, desalination cost trends.

The main parameters for technology selection for policy/decision makers are the total investment and produced water costs, the type of the project contract, and other parameters such as local incentives or subsidies. In fact, the cost of desalination with different processes is site-specific and depends on many parameters such as feed water salinity and other water quality parameters, plant capacity, energy and labor costs, type of the contract, political and environmental restrictions, and many other factors which are discussed in this paper. Selection of appropriate technology for any specific location thus requires an accurate methodology for each technology. The existing methodologies and software 
packages are of black box type and other available softwares do not take into consideration all of the parameters influencing the cost and their accuracy is limited to specific conditions [4].

The primary goal of the present paper is to present a review of the costing aspects and evaluate the main parameters influencing the total water cost produced by different desalination technologies. The recent developments that have contributed to cost reduction in different desalination technologies as well as energy consumption and hybrid systems will also be outlined. The main reasons for variation in total water cost of different recent desalination projects are also herein discussed. Also, when evaluating the cost of providing desalinated water, it is quite important to distinguish between the real cost of treating the water by a desalination technology and the actual cost of providing water to the consumer. Commonly, these are inadvertently mixed in various presentations and create confusion in comparisons of desalination cost. The delivery cost of desalted water to consumers includes administrative and conveyance costs and sometimes profit to the provider that have great variation. Some key factors are system losses and water provided without return of cost (system losses and theft). Therefore, in this analysis, the desalination cost assessment is aimed at true treatment costs.

\section{Desalination development potential and market forecast}

Desalination has great development potential on a global scale. This is attributed to the fact that, out of 71 largest cities that do not have local access to new freshwater sources, 42 are located along coasts [1]. Out of the entire world population, 2,400 million inhabitants representing $39 \%$ of the total, live at a distance of less than $100 \mathrm{~km}$ from the sea [3].

Other than the fact that desalination may be the only option for some countries, there are driving forces behind its development potential, making it more favorable than conventional resource development. Being independent of climatic conditions, rainfall and so on, a primary force is its identification as a secure source of supply. Desalinated seawater is truly a "new" water source and has 
an essentially unlimited capacity, not subject to sustainability criteria, although perhaps limited by energy production.

Desalination capacity is continuously increasing worldwide, not only in the Middle East and North Africa (MENA) region where water demand is high and other sources of supply are limited, but also in countries where desalination was unthinkable in the past such as in Spain and Australia (both contain arid and semiarid lands). It is expected that the total desalination market will reach over US\$31 billion by 2015 as shown in Table 1 [8]. About 50\% of the total desalination investments are for SWRO projects due mainly to its lower investment and total water cost compared to other conventional source development (where any exist), footprint size, and the continuing technological advances enabling RO desalination to treat higher raw water salinities such as Arabian Gulf seawater. Thermal processes will also continue to be utilized especially where energy is available at low-cost, but the tendency is that MED will replace MSF in future projects and could even compete with SWRO where raw water is highly polluted or of very high salinity. Thermal processes will remain in the market because they have been widely accepted in the Arabian Gulf area. They have a proven record of reliability, are dependable and have the potential for cogeneration of power and water (hybrid systems). However, because of the flexibility and simplicity of project bidding parameters and budgeting considerations, several recent SWRO plants were built along with new power plants instead of choosing the co-generation option with a thermal process. This will definitely help to keep the desalination cost stable due to competition with other technologies.

Table 1- Market historical and forecast of desalination systems [8].

\section{Trends in desalination contracts and project finance}


The key source to mobilize funding for these projects has been governments, but the size of foreseen investments has many governments convinced that the private sector has a role to play in this development. Also, many governments want to take advantage of private sector advances in technology and management. These factors have resulted in public-private transaction models that have been successful [3]. They are called Independent Water and Power Producers (IWPP). Other project delivery methods include Build Own Operate (BOO) or Build Own Operate Transfer (BOOT) contracts without initial government ownership, but with contract guarantees. Globally today, new projects are delivered with over $58 \%$ being privately financed, with Build Own Operate Transfer (BOOT) deliveries accounting for $28.9 \%$ and IWPP for $29.7 \%$ of the new projects [2].

Growth has also led to the tendency of consulting companies to exceed their conventional design role and become a part owner within a private developer structure for a desalination and/or power plant. Therefore, there is a need for identification and standardization of factors/parameters that contribute to the unit cost of desalinated water for each technology, and development of an appropriate costing methodology that accounts for all of these parameters. The use of different methodologies by different project delivery companies could be one of the causes of the low accuracy in estimating the water cost even for similar projects. If the main parameters influencing the water delivery cost, such as salinity, plant capacity, technology, energy cost, and regulatory requirements, are known in advance, then the total estimated water cost can be ascertainable to a reasonable degree. It is not reasonable that the other few specific parameters, including subsidies, financial and political risks, should affect the price, causing the considerable variations observed in project bidding.

Most of the recent desalination projects are privately-financed water projects under the BOO/BOOT delivery type. The arrangement of BOO involves a long-term supply contract with the client, who is charged accordingly for the services delivered (e.g., water, power, water and power). With a BOOT scheme, the project bid winner undertakes the same functions, but the project is transferred to the client 
at the end of the supply contract term. Therefore, the most important parameter influencing a BOO project award is the total water cost (TWC), which takes into account all of the parameters discussed above as well as the agreed price of energy and other local contingencies. The BOOT bid evaluation is slightly more complex because the project sponsor must evaluate the residual value of the facility at the end of the contract period. A small cost variation, such as US\$0.01 or less per cubic meter, can make a difference of hundreds of millions of US\$ of investment costs covered by the private sector/banks for a project. The Governments subsidies are usually not taken into consideration in the project financing. Within the BOO and BOOT concepts, governments buy the treated water from the companies at a fixed price and sell it to the population at a subsidized price [3]. In some cases, governments partner with local industries to obtain water which may be partially subsidized by the industry, and not the government or an international agency.

\section{Trends in desalination costs}

When desalination started in the late 1850's, the cost was not as important since the main challenge was to produce fresh water from seawater for boilers and drinking purposes in ships. Later in the 1960's and early 1970's, desalination technologies (thermal processes) were widely available for commercial production but the cost was still too high. Membrane processes began to compete in the 1970's and started the trend toward cost reduction. As late as 1975, seawater desalination costs were quoted in planning documents as being about US\$2.10/m³ (Southwest Florida Regional Planning Council, 1980).

The expansion of the desalination market has attracted many organizations and companies to improve desalination technologies to reduce the costs. Tremendous decreases in desalination costs were continuously achieved in the last decades causing the water price to reach US $\$ 0.50 / \mathrm{m}^{3}$ [9] for large scale SWRO plants and for specific local conditions and below US $\$ 1.00 / \mathrm{m}^{3}$ for MSF. Technological 
maturity, system integration, and competition combined to cause the reduction of desalination costs in the last 20 years. Figure 2 shows the important decrease in the price reaching a factor of 10 for MSF.

Figure 2. Unit water cost trends by SWRO and MSF processes.

Similarly, technological improvements in membrane design and systems integration have also decreased the desalinated brackish water cost down by over half in the last two decades. In some systems, the amount of energy required to produce $1 \mathrm{~m}^{3}$ of fresh water decreased by over $64 \%$ [10]. It is more difficult to estimate brackish water cost because of water quality and quantity changes from site to site and sometimes even at the same site [11]. But, brackish water cost is always lower than SWRO mainly due to lower salinity feed water which requires lower applied pressure and allows higher recovery. This causes a lower energy consumption per unit volume of water produced and a substantially lower investment cost. Low cost potable water quality from a brackish water source can also be achieved by electrodialysis reversal (EDR) technology. A very large scale brackish water desalination plant, with a total capacity of $200,000 \mathrm{~m}^{3} / \mathrm{d}$ and using EDR technology, was built recently in Barcelona, Spain. Typically, EDR is selected over RO for systems that have a particular water chemistry issue, such as a high sulfate to chloride ratio in the raw water.

Although desalination is expensive compared to conventional treatment of fresh water, the cost of desalination, particularly RO, is decreasing, while the costs for developing new fresh water sources of potable supply are increasing or no longer possible. Membrane prices have significantly dropped in the last decades. Prices of thermal processes are also falling due to material improvements, process innovation, and increasing competition. Also, as technological developments cause a reduction in the cost of equipment, the overall relative plant costs are expected to decline. This trend has made desalination, once a costly alternative to the provision of potable water, a viable solution and 
economically competitive with other options for water supply. Figure 3 shows the cost trends for different raw waters treated by RO [12]. It shows that the cost of desalination and water reuse has reduced to a level comparable with traditional water supply options. RO desalination cost includes all the treatment steps including pretreatment and post-treatment processes but excluding water distribution costs. The overall decline in cost trend may significantly decrease or could reverse based on current, substantial increases in conventional energy production costs.

Figure 3. Water resources cost trends [12].

\section{Technology developments that have contributed to cost reduction}

\subsection{Thermal processes}

The main factors that contributed to cost reduction in all desalination processes are the significant improvements in the performance of these technologies during the last few decades. The main improvements in thermal processes are summarized in Table 2. In addition, the BOO and BOOT contract delivery mechanisms, which changed from technical to functional, have allowed project bidders to further optimize plant design and operation, which has helped in reducing the cost.

Table 2. Main improvements of thermal processes.

More details on developments that have contributed to cost reduction are presented in section 6.

\subsection{Membrane processes}


Many recent and important improvements in desalination technologies are in RO systems. The total desalination capacity worldwide using RO technology is continuously increasing, even in the Arabian Gulf region where energy is cheap and raw water quality is less suitable for RO technology, requiring an advanced pretreatment scheme to protect RO membranes mainly from fouling and biofouling [17]. The total global capacity (sea and brackish waters) of RO is the highest compared to any other process (Figure 1). The tremendous reduction in desalinated water cost by RO has enabled many countries to implement desalination to supply potable water for domestic and industrial use and even for agriculture purposes in some countries such as Spain [18].

There have been many developments over the last three decades that have contributed to a reduction in unit water cost of RO desalination, particularly membrane performance and reduction in energy consumption caused by more efficient energy recovery systems. The performance of the membrane materials and modules has improved with respect to increased salt rejection, increased surface area per unit volume, increased flux, improved membrane life, and capacity to work at higher pressure, and has also a decreased membrane cost. The recovery ratio increased considerably over the years due to improved salt rejection. The recovery ratio for normal seawater desalination $(35,000 \mathrm{mg} / \mathrm{L}$ of salinity) was about $25 \%$ in 1980 s and it increased to $35 \%$ in 1990s. Currently, it is about $45 \%$ and can reach $60 \%$ if second stage is applied. Significantly lower recoveries occur in locations where seawater salinities are usually high, such as the Arabian Gulf, the Red Sea, and the eastern Mediterranean Sea, but recoveries in these difficult areas have also historically improved. Improved recovery has facilitated a decrease of the investment cost and also operating costs. The capital cost reduction occurs because of the reduction in RO train and intake and outfall system capacities caused by the improved conversion rate of seawater to fresh water. The operating cost reduction is due to a reduction in usage of chemicals and pumping energy [19]. 
Membrane costs should increase due to inflation over a period of time. The significant decrease of membrane costs of the last decades has contributed considerably to unit water cost reduction.

Perhaps the energy component has witnessed the most dramatic improvement in RO processes. The energy is recovered from the brine side of the process through either turbo systems that include reversible pumps, Pelton turbines, turbochargers, and a hydraulic pressure booster or through volumetric systems that include the ERI pressure exchanger, DWEER (Dual Work Exchanger), or the KSB (SalTec) devise. Other new energy recovery systems are under development with the objective of reducing energy consumption for SWRO below $2 \mathrm{kwh} / \mathrm{m}^{3}$. Typical energy consumption for different desalination technologies is presented in Table 3, section 6.2.

The other important improvements in RO technology are:

- Improvements in pretreatment processes (including microfiltration (MF)/ultrafiltration (UF) membranes). Most of the new plants are using lesser amounts of chemicals, which is more environmentally friendly and results in a great reduction in consumable costs [20].

- Development of new intake designs, mainly conventional wells [21], horizontal wells or drains, or gallery intakes [22]. These types of natural filtration systems are very suitable for treatment of difficult raw water qualities to minimize impingement and entrainment [23], and reduce quantities of chemicals used, especially during red tide events or high harmful algal blooms [21, 22]. In open intakes, a more suitable pretreatment is required to deal with red tides. Dissolved air flotation (DAF) is the best solution for red tides today.

- Improvements in design with use of different configurations and improvements in linking processes.

- Development of a high boron rejection membranes that produce an acceptable concentration in the permeate without requiring a second pass RO system [24]. 
- Reduction in usage of chemicals with improved membrane performance. Injection of acid and antiscalant is not always necessary. A recent study showed stable operation of a SWRO plant free of chemicals without causing any scaling [25]. In addition, the use of low pressure membranes in SWRO pretreatment can reduce or avoid the use of coagulation agents [20].

- Increase in plant capacity (plant size and unit size) provides a scaling factor that reduces cost, particularly capital cost per treatment capacity unit (Figure 4).

Apart from improvements in RO technology, increases in plant capacity have also contributed to a reduction in unit water cost (Figure 4) [18]. The magnitude of the respective costs due to improvements in the membranes and increases in plant capacity are difficult to measure since they have both taken place simultaneously. Plant capacities increased by a factor or 10 between 1995 and 2010.The Maqtaa SWRO plant located in Algeria, which is under construction, will have a total capacity of $500,000 \mathrm{~m}^{3} / \mathrm{d}$ [26].

Figure 4: Investment costs in RO processes vs. capacity [18].

\subsection{Hybrid systems}

Two or more desalination processes can be combined or coupled with a power plant in a hybrid configuration to produce water at low cost. Where there is considerable fluctuation in water and power demands, it is very suitable to use hybrid desalination systems (co-generation power-MSF plant with SWRO plant). In general, MSF or MED are combined with VC and RO or nanofiltration (NF). Combination of processes and power production can more efficiently utilize fuel energy as well as the produced power. For utilization of idle power to produce water via RO or MVC, the additional 
produced water can be stored in aquifers and recovered when demand is higher, thereby increasing overall system efficiency and reducing cost [27].

There are many advantages of hybrid systems. Different desalination technologies can use common intake and outfall systems to reduce pumping energy and decrease the cost of civil works. Also, the feed water temperature to the $\mathrm{RO}$ process can be maintained constant during the seasons using the available waste heat from thermal brine discharge. Use within the RO process, in turn, helps cool the water to acceptable temperatures before the concentrate is returned to the sea, thus, better meeting discharge regulations related to thermal discharge cooling water. Furthermore, integrated pretreatment and posttreatment can reduce energy and chemical consumption.

When thermal-based and membrane-based technologies are used simultaneously, the product waters of both processes can be blended to obtain the required product quality for potable use. Also, a second pass RO may not be required, if blending is used to obtain specific water quality (addition of hardness). This combination significantly reduces the investment and total water costs. For example, a plant producing $150,000 \mathrm{~m}^{3} / \mathrm{d}$ with an optimum capacity ratio of $\mathrm{SWRO}$ to $\mathrm{MSF} / \mathrm{MED}$ of 2 (i.e. $100,000 \mathrm{~m}^{3} / \mathrm{d}$ RO and 50,000 $\left.\mathrm{m}^{3} / \mathrm{d} \mathrm{MSF} / \mathrm{MED}\right)$, the total water cost is decreased by US $\$ 0.064 / \mathrm{m}^{3}$, which creates an economic benefit of approximately US\$3.4million/year. The total savings used for this benefit were derived from the economic assessment of hybrid system graphs developed by Awerbuch [28].

\section{Parameters influencing the desalination cost}

\subsection{Main parameters influencing the cost}

The parameters that affect the total investment (capital) and operational costs of desalination plants are the major factors considered in selection of an appropriate desalination technology. The estimated 
cost of desalination with different processes is site-specific and depends mainly on the following parameters:

- Electric power availability. If a plant is going to be a stand-alone facility powered by electricity generated at a considerable distance away, the RO process may have greater economic advantage over a thermal or hybrid process.

- Desalination process configuration, plant size and its component design. The investment cost of different commercial desalination technologies differs widely between thermal-based and membrane-based technologies (Table 3). For a similar plant capacity, thermal processes require larger footprints and use more costly materials and equipment than the SWRO process. Similarly, thermal processes consume higher amounts of specific energy (electrical and thermal) than RO (needs electricity only) and more chemicals are required to control scaling, corrosion and foam. However, on the other hand, thermal distillate is of higher quality than the RO product. Also, thermal processes function using nearly any quality (salinity) of feed water without extensive pretreatment. Plant capacity is also an important issue. Normally, the higher the plant capacity, the lower the total water cost and investment cost per cubic meter of product (Figure 4). However, political or environmental issues could be a limitation for successfully implementing such megaprojects.

- Geographical location and site-specific characteristics. Desalination plants with a required production capacity should be built in appropriate locations to avoid additional costs, such as water transfer or not running the plant under its optimal conditions. Real estate acquisition cost is also a significant factor that may require greater water transmission in locations where land cost may exhibit orders of magnitude differences in relatively short distances.

- Raw water quality, temperature, intake arrangement and required product water quality (posttreatment, blending). The plant location should be carefully selected at the best site in terms of feed 
water quality, elevation or currents especially for RO as the cost could be significantly affected by the quality of feed water if more advanced pretreatment is required. For example, biofouling reduces the membrane life-expectancy and increases the operation and maintenance (O\&M) costs and, in some cases, has led to temporary plant shutdowns. Intake and pretreatment arrangements are designed depending on raw water quality and quantity as well as geology of the site.

- Reject discharge type and product water storage. New environmental regulations continuously oblige designers and plant constructors to develop advanced methods for concentrate discharge [29]. Concentrate salinity and chemistry, temperature (for thermal processes), and waste chemicals are the main concerns $[29,30]$. New regulations require dilution of the concentrate in a mixing zone, reduction of brine temperature by cooling water, and removing the chemicals before discharging it into the sea (e.g., dechlorination).

- Post-treatment of the product water. The $\mathrm{pH}$ and hardness of desalinated water requires readjustments to make the water acceptable for potable use [31]. In general, desalinated water, after post-treatment, is introduced into the water distribution system.

- On-site storage of product water. Depending on the reliability of the treatment plant infrastructure and the electric power source and the need for storage of produced water for emergency periods, onsite storage capacity can range from a few hours of plant capacity up to about 5 days of capacity. At the large desalination plants in the Middle East region, only a small amount of water is stored in tanks in case of a reduction in water production due to routine or an unexpected shut down [32].

- Product water recovery and energy price. The energy price is included in the contract agreement for the service period as part of the total water cost. However, virtually all BOO and BOOT contracts contain an energy adjustment cost provision to cover variations (mostly increases) in electric power costs. Therefore, minimization or reduction in the facility energy consumption has a major impact on reducing the unit water cost (Figure 7). 
- Materials, equipment, chemicals and other consumables.

- Financing details and amortization period as well as inflation.

- Contract (land and construction, cost inflation during the life of the plant), interest rate changes, and administrative overheads.

- O\&M, membrane replacement, equipment replacement (particularly pumps and header pipes), skilled labor costs and training requirements. The availability of qualified personnel results in higher production capacity with less shutdown and consumables use [1]. However, in regions where the skilled labor pool is insufficient or non-existent, operational costs can be higher due to higher wages for plant workers (imported skilled labor) or plant inefficiencies caused by poor operation.

- Investment and capital costs depend strongly on the above parameters, especially the desalination process.

- Specific details of the water purchase agreement, regulatory requirements and political risks (higher financing rates).

- Competitive bid/contract type (BOO, BOOT, IWPP).

- Performance standard. Many BOO and BOOT bid tenders contain a minimum performance reliability standard. Typically, a 95\% standard is applied. If a 98\% standard is applied, there is a substantial increase in CAPEX because of the increased requirement for redundancy of equipment. The big issue is loss of production and it is huge. It can be as much as US\$1 million/d and CAPEX is not the driver - OPEX is the key. In mega-plants, one additional train (unit) is usually used as a spare that operates in emergencies. Use of the excess capacity can decrease the flux and extend the membrane life. It also gives flexibility for regular maintenance (basically 2 weeks/year) and membrane replacement (usually one-fifth to one-seventh of the modules each year) and provides smoother operation in term of pressure drop. So at $95 \%$ uptime, we only have 2.61 weeks off anyway which merely leaves 0.61 weeks for unplanned downtime. The point here is that the 
desalination plant has to work in conjunction with the mining equipment in order to maximize cash flow. No rational contract contains a $100 \%$ reliability standard. There is commonly a penalty clause for not meeting the performance standard.

Another issue to consider here is the capacity of the storage tanks (the tank feeding the pipeline and storage tanks in between and the tank at the site or a covered pond)?

\subsection{Capital, investment and total water costs}

The capital cost includes all expenditures associated with the implementation of a given desalination project from the time of its conception, through design, permitting, financing, construction, commissioning and acceptance testing for normal operation [33]. Capital cost is often referred as CAPEX or Capital Expenditure [34].

TWC or life-cycle cost is the sum of capital cost and operating cost for the contract period (Figure 5). The cost is calculated by dividing the sum of the amortized (annualized) capital costs and the annual O\&M costs by the average annual potable water production volume. In general, TWC excludes the distribution costs, particularly in alternative delivery contracts (in municipal water costing, the distribution costs are included in the overall water cost assessment) [33]. O\&M costs are site-specific and consist of fixed costs and variable costs. Fixed costs include insurance and amortization (annual interest for direct and indirect costs) costs. The primary variable operating costs (OPEX) include the cost of labor, energy, consumables (chemicals, membrane replacement, pump replacement), maintenance, and spare part costs, which are dependent on the relationship of facility location to manufacturing and distribution centers.

Figure 5: Diagram of TWC analysis for desalination processes. 
Capital cost includes direct and indirect costs. Direct capital costs represent the installed process equipment, auxiliary equipment (MSF/MED equipment is generally more costly than RO), and the associated piping and instrumentation, site civil works, intake (may include wells, open or sub-surface intakes) and brine discharge (may include outfall, injection wells, evaporation ponds) infrastructures, buildings, roads and laboratories. Land cost depends on the contract agreement and may vary from zero to an agreed lump sum depending on the site characteristics [35]. Construction costs are typically 50$85 \%$ of the total capital cost. Indirect capital costs represent interest during construction (overheads), working capital, freight and insurance, contingencies, import duties (in some cases waived), project management, and architectural and engineering (A\&E) fees. These costs are usually calculated as a percentage of the direct capital costs with an average of 40\% [35], 15-50\% [33] or 30-45\% [36], but are very project specific.

The investment cost depends strongly on the mentioned parameters. Table 3 provides the estimated minimum and maximum limits of investment and TWC for different technologies of recent, newly contracted and commissioned projects. The actual energy consumption is four times higher than the minimum energy required to produce fresh water from seawater (thermodynamic limit of desalting typical seawater $(35 \mathrm{~g} / \mathrm{L})$ is $0.78 \mathrm{Kwh} / \mathrm{m}^{3}$ for $0 \%$ recovery and $1.2 \mathrm{Kwh} / \mathrm{m}^{3}$ for $50 \%$ recovery, which is closer to an RO system recovery). Figure 4 shows the difference in investment cost for RO plants of different sizes [18]. The same general trend of the curves is observed for seawater and brackish water. TWC and investment costs of the Barcelona brackish water EDR plant, having a total capacity of $200,000 \mathrm{~m} / \mathrm{d}^{3}$ and feed salinity of $2 \mathrm{~g} / \mathrm{L}$ (obtained product $<400 \mathrm{ppm}$ ), are US $\$ 0.26 / \mathrm{m}^{3}$ and US\$79.56 million, respectively [2]. TWC for large-scale thermal process facilities ranges from US\$0.80 to 1.50 , US\$0.70 to 1.20 , and US\$0.60 to $1.00 / \mathrm{m}^{3}$ for MSF, MED and VC, respectively. However, it is important to mention that the total energy consumption for each technology is a better parameter in comparing the cost as in most cases energy (especially thermal) is highly subsidized by governments in 
energy rich countries making the TWC an ineffective parameter for cost comparison between plants located in different countries.

\section{Energy consumption}

Table 3: Energy consumption and water cost (average values) of large scale commercial desalination processes $[2-4,8,13,14,16,18]$.

The breakdown of the total energy consumption of two real SWRO plants, typically reported as 3-4 $\mathrm{kwh} / \mathrm{m}^{3}$ excluding water distribution systems (Table 3), is presented in Figure 6. Both plants use similar conventional pretreatment and open intakes.

Figure 6: Energy consumption in SWRO: (left) one-pass RO, salinity= $35 \mathrm{~g} / \mathrm{L}$; (right) 2-pass RO, salinity=39 g/L.

In MED the specific power consumption is below $2 \mathrm{kWh} / \mathrm{m}^{3}$ of distillate, which is significantly lower than MSF which is typically $4 \mathrm{kWh} / \mathrm{m}^{3}$. The major advantage of the MED process, however, is the ability to produce significantly a higher performance ratio in excess of $8.6 \mathrm{~kg}$ of the product per $0.45 \mathrm{~kg}$ of steam whereas the MSF practical limit is only 10.

If the corrosion and scaling potentials are reduced through some means such as the application of the NF membrane softening process, then these plants can be operated at higher temperatures with a corresponding increase in efficiency and significant decrease in the cost [28].

The described improvements helped in reducing the unit water cost produced by MSF to less than US $\$ 1.00 / \mathrm{m}^{3}$ for large-scale plants. The investment cost of large MSF plants is about US $\$ 1,500 / \mathrm{m}^{3} /$ day 
capacity based on the average value of recently contracted plants installed in the Middle East.

Additionally, MSF contractors have been able to reduce the construction time, thus implementing large turnkey projects within a period of close to one year, which is responsive to meeting water shortages on an emergency basis. A typical unit water cost breakdown for an MSF plant is given in Figure 7-left [33]. Energy (mostly steam) and capital recovery represent 74\% of the MSF cost, O\&M 17\%, and spare components $9 \%$.

Figure 7: Unit water cost breakdown for MSF (left) and RO (right) [33].

The investment cost of a recent large scale SWRO desalination plant ranges between USD \$900-

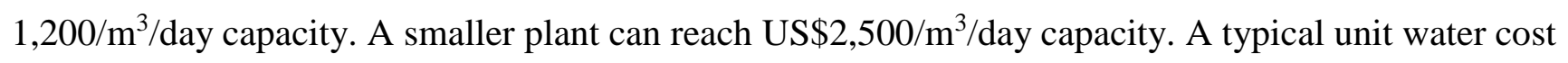
breakdown for a SWRO plant is given in Figure 7-right [33]. TWC varies between US $\$ 0.5$ to $1.20 / \mathrm{m}^{3}$. Capital, energy and membrane replacement costs constitute the major components of TWC. Capital amortization constitutes $35 \%$ to $45 \%$, whereas electric power is $19 \%$ to $40 \%$ of the TWC. Conversely, in BWRO, energy represents about $10 \%$ of the total cost due to a lower operating pressure, $65 \%$ capital amortization, and $25 \%$ O\&M and labors costs [33].

Also, it is important to note that the number of operating RO plants is increasing worldwide including in energy-rich countries as RO capital cost is lower than MSF and the technology has had tremendous developments. Even MED costs, which are comparable to RO, have declined, but there are many fewer MED plants being constructed. This phenomenon is observed for new projects with water and power production on the same site where RO is built along with very large scale power plants, such as the case of the Barka and Dhofar plants in Oman. This trend towards selective use of RO over a thermal process reflects the flexibility and simplicity of bidding requirements for the RO process. 


\subsection{Cost of some recent desalination projects}

Some recent TWCs of various desalination plants using different technologies and contracts type are summarized in Table 4. It shows costs with significant differences in total price even for similar plant capacities and project types. In some projects, water price is high due to specific conditions like the necessity to install complex pretreatment systems or because of severe environmental regulations that increase permitting and construction costs. A detailed list of several seawater desalination plants installed around the world and their associated TWCs were published in DWR 44-33 [2] and Huehmer et al. [34].

Table 4. Water cost of different recent large scale projects [2, 8].

\section{Variation in the cost of desalinated water}

Figure 8 shows that the TWC decreased significantly from 1991 to 2003 mainly due to the technological developments described. But, when TWC is extended a little further into the future, the projected cost curve begins to turn upwards (dotted line). For the low unit price of the Singapore plant (US $\$ 0.47 / \mathrm{m}^{3}$ ) [9], the cost is based on a guaranteed minimum water production significantly lower than the plant production capacity [8]. Ashkelon is an impressive case since the cost is low even though the salinity of feed water is higher and the product has a chloride limit of $35 \mathrm{mg} / \mathrm{L}$ and a boron limit of 0.4 $\mathrm{mg} / \mathrm{L}$. However, it was reported that TWC was adjusted many times and increased to US $\$ 0.655 / \mathrm{m}^{3}$ in 2006 and to US $\$ 0.778 / \mathrm{m}^{3}$ in 2008 [18]. Some projects include extraordinary costs such as complicated offshore intakes or extensive environmental mitigation measures.

Figure 8. TWC of different SWRO plants in operation and contracted (average capacity ' $\mathrm{m}^{3} / \mathrm{d}^{\prime}$ and average cost ' $\mathrm{US} \$ / \mathrm{m}^{3}$ ' for each year). 
The use of different methodologies by different construction companies could be one of the reasons that such differences in estimating the water cost occur, even for similar projects because the main parameters influencing the cost such as salinity, plant size, technology, energy cost, and regulatory requirements are known in advance and should not affect the TWC. However, other specific parameters such as subsidies, financial and political risks are also contributing to evaluation of the costs, causing some variations in observed project bid values.

Cost of desalination commonly is not directly related to charges for delivered potable water charged by a utility or contractor. There are no precise rules to estimate comparable prices charged for desalinated water even for similar conditions and plant types, because the costs added for administration, delivery or special delivery covenants (profit) are quite variable. Therefore, a uniform cost estimation technique developed for desalination will benefit water users and utilities using a contractor to provide water to evaluate actual delivery costs within a global context.

\subsection{Some reasons for the recent increased TWC and the impact of emerging desalination technologies on cost variation in the future}

After extensive investigation of the TWC evolution over the last decades and for recent projects, the authors join the expectation of many desalination experts that the desalinated water cost will not reduce further at the same rate of decline for several reasons. The primary reasons are the instable prices of crude oil (affects energy costs), currency fluctuations, and increases in membrane prices. Membrane prices were kept stable in the last years by technology improvements and competition causing many companies to operate at low profit margins. Many membrane manufacturers predict that there is no way to avoid membrane price increases in the near future [8]. Most of membrane manufacturers have already increased the prices of their products. Another important issue is the increased costs of energy, shipping, 
raw materials (particularly specialty metals), equipment and chemicals prices along with more restrictive environmental regulations. Furthermore, in some projects, intake and reject disposal systems costs are higher than the cost of the entire capital cost of a similar plant in another country where restrictions are not severe (e.g. Australian plants). Short supply of highly skilled manpower for plant construction and O\&M could also be a factor in cost increases $[1,37]$. Finally, currency fluctuations and inflation will oblige constructing companies to increase their financial risk percentage within the financing framework.

Expected improvements in existing technologies, such as optimization of chemical dosing, posttreatment [31], and new cleaning methods (without shutting down the desalination unit) may not significantly reduce the cost of desalination in the future.

Existing desalination technologies are mature and desalinated water cost reductions will be marginal due to further developments in technologies. However, there is some scope of improvements in membrane processes due to improved membranes, higher efficiency pumps and energy recovery systems (including integrated systems) and pretreatment methods. New design configurations (interstaged membrane operations) [38] and use of forward osmosis [39] can also reduce energy consumption in SWRO. The use of 16-inch RO modules can also have an impact on cost (mainly lower footprint) despite designers of construction companies are still reluctant to use these mega-modules which were developed several years ago. Other technological improvements in advanced membrane materials such as development of sulfonated polysylfone composite RO membranes that are highly resistant to chlorine attack (better biofouling control) [40] are foreseen, which could have an effect on reducing the cost as well [7].

However, development of new low-cost technologies such as adsorption desalination [41], membrane distillation (MD) and new hybrid systems using renewable energies and low grade waste 
energy will likely bring the cost down, but implementation of these new technologies will take some time to compete with the existing processes.

In thermal processes, there could be some improvements in the future with the use of NF process for pretreatment in order to control scaling at higher top brine temperatures [42], and development of thermal-based hybrid systems using renewable energies such as geothermal, solar or wind energies [4346].

\section{Review of existing desalination costing methodologies}

Details of the most well-known software packages for estimating the capital and O\&M costs for various desalination processes, such as DEEP "Desalination Economic Evaluation Program” and WTCost $\odot$, developed by International Atomic Energy Agency (IAEA) [47] and the US Bureau of Reclamation with the assistance of I. Moch \& Associates and Boulder Research Enterprises, respectively, were presented by Reddy and Ghaffour [4]. The seawater desalting costs program of Leitner and Water Resources Associates (WAR) were also discussed [4, 48].

Desalination cost assessment methods are required by many different types of users and for different purposes, thus there are different accuracy requirements. In general, plant suppliers and consultants develop their own spreadsheet cost estimation methods which are proprietary and generally with less transparency. Other specialists use the published tools such as DEEP, WTCost $\subsetneq$ and SWRO cost estimator [2]. To evaluate the accuracy of these tools, different authors have used these software packages [35, 49-51] which were recently developed for different RO and thermal desalination plants in operation in order to evaluate the calculated costs and compare them with actual data for the same conditions. Estimated costs of the same plants were found to have varying accuracies with errors as large as $20 \%$. Then, authors used another simple spreadsheet cost calculation prepared by Tua Engineering, Malta, for RO [52] and Ettouney et al. [35] for thermal processes (spreadsheet developed 
for the Middle East Desalination Research Center (MEDRC) project) and found similar figures which means that the complex parameters used in these software packages are not widely influencing the cost estimates. Similarly, comparable figures were presented by Huehmer at al. [33] using the results of different empirical capital cost models for SWRO developed by different authors [53-57].

If the existing cost estimation methodologies were more transparent, it would help researchers and users to develop more accurate tools taking into account all the possible parameters influencing the water cost in order to converge towards comparable costs. However, reasonable variation in costs is acceptable as it remains site specific. These tools are needed for selection of the appropriate technology for specific sites, selection of optimum production capacity of each technology, including hybrid desalination configurations, minimization of desalinated water cost by optimizing capital and operating costs, and for selection of appropriate desalination technology powered with different energy sources fossil fuels, nuclear or renewable energies [58-60].

The total project investment (capital) and desalinated water costs are needed by different levels of people and sectors for different purposes as they are the main factors for decision-makers and investors to consider desalination as a solution for potable water supply. Policy/decision makers and planners need these tools for use in feasibility studies and consultants need them for evaluation of tenders. Plant suppliers use cost estimation software packages for evaluation and optimization of their technologies and processes, whereas design engineers use them for process and equipment design optimization. Researchers and technology developers also need transparent cost estimation methodologies for improving existing desalination technologies and for developing new technologies in order to reduce further the cost of desalination.

\section{Conclusions}


The investment and total water costs are primary parameters used by decision makers to select the appropriate desalination technology for a project based on plant capacity, energy consumption, contract delivery type, and other factors, such as the cost to mitigate for environmental impacts. However, cost depends on many parameters and the accuracy of a cost estimate relies on the use of more transparent, high quality software packages to produce accurate results. Cost data reported is commonly not consistent for different technologies or similar-sized facilities, because they are site-specific. Available cost estimation methods and software packages are of different accuracy with error ranges of \pm 10 to $50 \%[4]$.

It is quite clear that there is a need to decide on the complexity and content of cost estimation models. Water cost estimation methodologies need to identify and specify all of the parameters that contribute to the desalination cost and develop a structured and transparent procedure for estimation of the desalinated water cost for any facility. These estimates are needed for project planning and budgeting as well as for feasibility studies.

Desalination costs are decreasing for all technologies, particularly in the last decade with the largest cost reduction occurring in $\mathrm{RO}$ technology. The reduction in $\mathrm{RO}$ treatment cost has been favored by the growth rate, plant capacity, competition with other technologies, and the vast improvements in RO systems (better process designs, membranes and materials, and lower energy consumption) as well as the simplicity and flexibility of recent project bids. However, the authors believe that desalination costs will not continue to decrease at the same rate in the near future, despite continued improvements in the existing technologies. Equipment, raw materials, and energy costs are rapidly rising which will impact future capital and operating costs.

Environmental guidelines are becoming stricter, particularly in the United States, the European Union and Australia. These regulations cause a significant increase in cost as permitting becomes a major factor (in California the permitting cost can be up to $60 \%$ of a major project cost). Similarly, 
manufacturers of chemicals are under continuous pressure, particularly in Europe to register, evaluate, and obtain authorization for use. This is a costly endeavor and will also reflect on the cost of desalination.

\section{Acknowledgments}

Authors wish to Thank Mr. Kenneth Goodboy, Global Director Desalination, Hatch Water, USA, for his advice and Mr. Muhannad AbuGhdeeb, Engineering Specialist at WDRC-KAUST, for his time in designing the energy and cost figures.

\section{References}

[1] N. Ghaffour, The challenge of capacity-building strategies and perspectives for desalination for sustainable water use in MENA, Desalination and Water Treatment 5 (2009) 48-53.

[2] Global Water Intelligence (GWI/IDA DesalData), Market profile and desalination markets, 2009 2012 yearbooks and GWI website: http://www.desaldata.com/

[3] K. Quteishat, Desalination and water affordability, SITeau International Conference, Casablanca, Morocco, January 2009.

[4] K.V. Reddy and N. Ghaffour, Overview of the cost of desalinated water and costing methodologies, Desalination 205 (2007) 340-353.

[5] N.M. Wade, Technical and economic evaluation of distillation and reverse osmosis desalination processes, Desalination 93 (1993) 343-363.

[6] J. E. Miller, Review of water resources and desalination technologies: Sandia National Laboratories, Report 2003-0800, 54, 2003.

[7] L.F. Greenlee, D.F. Lawler, B.D. Freeman, B. Marrot, P. Moulin, Reverse osmosis desalination: water source, technology, and today's challenges, Water Research 43 (2009) 2317-2348.

[8] T. Pankratz, MEDRC workshop on Membrane Technology Used in Desalination and Wastewater Treatment for Reuse (www.medrc.org), Muscat, Oman, March 2008.

[9] F.H. Kiand, Supply of desalinated water by the private sector: 30 MGD Singapore seawater desalination plant, MEDRC International Conference on Desalination Costing, Conference proceeding, Lemesos, Cyprus, December 2004. 
[10] T.M. Missimer and S.A. Storves, Feedwater quality variation and the economics of water plant operation: The Island Water Association brackish water RO treatment facility, Sanibel Island, Florida: Proceedings of the World Conference on Desalination and Water Reuse, Bahrain, 11 , 2002.

[11] W. Arras, N. Ghaffour and A. Hamou, Performance evaluation of BWRO desalination plant - A case study, Desalination 235 (2009) 170-178.

[12] Alfred Stikker, GWI, Market profile: Desalination markets 2006.

[13] R. Borsani, S. Rebagliati, Fundamentals and costing of MSF desalination plants and comparison with other technologies, Desalination 182 (2005) 29-37.

[14] C. Sommariva, H. Hogg, K. Callister, Cost reduction and design lifetime increase in thermal desalination plants: Thermodynamic and corrosion resistance combined analysis for heat exchange tubes material selection, Desalination 158 (2003) 17-21.

[15] R. Matz, U. Fisher, A comparison of the relative economics of seawater desalination by vapor compression and reverse osmosis for small and medium capacity plants, Desalination 36 (1981) 137-151.

[16] M.A. Darwish, N.M. Al-Najem, Energy consumption and costs of different desalting systems, Desalination 64 (1987) 83-96.

[17] J.S. Vrouwenvelder, C. Hinrichs, W.G.J. van der Meer, M.C.M. van Loosdrecht, J.C. Kruithof, Pressure drop increase by biofilm accumulation in spiral wound RO and NF membrane systems: Role of substrate concentration, flow velocity, substrate load and flow direction, Biofouling 25 (2009) 543-555.

[18] A. Maurel, Seawater/brackish water desalination and other non-conventional processes for water supply, $2^{\text {nd }}$ edition book, Lavoisier, ISBN 10:2-7430-0890-3, 2006.

[19] C. Sommariva, Desalination Management and Economics book, sponsored by Mott MacDonald and published by Faversham House Group, UK.

[20] S.K. Al-Mashharawi, N. Ghaffour, M. Al-Ghamdi, G.L. Amy, Evaluating the efficiency of different MF and UF membranes used as pretreatment for RO Red Seawater desalination, in press, http://dx.doi.org/10.1080/19443994.2012.699449, Desalination \& Water Treatment.

[21] N. Voutchkov, Beach wells vs. open surface intake, Water and Wastewater International 19(2004) 22-23.

[22] T. Peters, D. Pintó, Seawater intake and partial pre-treatment with Neodren - results from investigation and long-term operation, Desalination and Water Treatment 24 (2010) 117-122. 
[23] S. Lattemann, M.D. Kennedy, G. Amy, Seawater desalination - A green technology? Journal of Water Supply: Research and Technology - AQUA 59 (2010) 134-151.

[24] K. Rahmawati, N. Ghaffour, G.L. Amy, Boron removal efficiency from Red Sea water using different SWRO/BWRO membranes, in press, http://dx.doi.org/10.1016/j.memsci.2012.09.004, Journal of Membrane Science.

[25] T. Waly, S. Saleh, M.D. Kennedy, G.J. Witkamp, G. Amy, J.C. Schippers, Will calcium carbonate really scale in seawater reverse osmosis?, Desalination and Water Treatment 5 (2009) 146-152.

[26] N. Drouiche , N. Ghaffour, M.W. Naceur, H. Mahmoudi, T. Ouslimane, Reasons for the fast growing seawater desalination capacity in Algeria, Water Resources Management 25 (2011) 27432754.

[27] R.G. Maliva, W. Guo, T.M. Missimer, Aquifer storage and recovery: Recent hydrogeological advances and system performance, Water Environment Research 78 (2006) 2428-2435.

[28] L. Awerbuch, Hybridization and dual purpose plant cost considerations, MEDRC International Conference on Desalination Costing, Conference proceeding, Lemesos, Cyprus, December 2004.

[29] S. Lattemann, T. Höpner, Environmental impact and impact assessment of seawater desalination, Desalination 220 (2008) 1-15.

[30] T. Hopner and S. Lattemann, Chemical impacts from desalination plants - a case study of the northern Red Sea, Desalination 152 (2002) 133-140.

[31] Y. Gacem, S. Taleb, A. Ramdani, S. Senadjki, N. Ghaffour, Physical and chemical assessment of MSF distillate and SWRO product for drinking purpose, Desalination 290 (2012) 107-114.

[32] N. Ghaffour, T. Missimer, G.L. Amy, Combined desalination, water reuse and aquifer storage and recovery to meet water supply demands in the GCC/MENA region, in press, http://dx.doi.org/10.1080/19443994.2012.700034, Desalination \& Water Treatment.

[33] M. Wilf, L. Awerbuch, C. Bartels, M. Mickley, G. Pearce and N. Voutchkov, The guidebook to membrane desalination technology, Balaban Desalination Publications, 2007.

[34] R. Huehmer, J. Gomez, J. Curl, K. Moore, Cost modeling of desalination systems, International Desalination Association (IDA) Congress, 2011, Perth, IDAW/PER11-302.

[35] H. Ettouney, H. El-Dessouky, R.S. Faibish, P.J. Gowin, Evaluating the economics of desalination, Chemical Eng. Proc. 98 (2002) 32-39.

[36] I. Moch, JR; I. Moch \& Associates, Inc., Wilmington de USA, A $21^{\text {st }}$ century study of global seawater reverse osmosis operating and capital costs, BHRO1-16, AWWM conference, Atlanta GA, USA, March 2003. 
[37] H. Mahmoudi, O. Abdellah, N. Ghaffour, Capacity building strategies and policy for desalination using renewable energies in Algeria, Renewable and Sustainable Energy Reviews 13 (2009) 921926.

[38] M. Elimelech and W. A. Phillip, The future of seawater desalination: Energy, technology and the environment, Science 333 (2011) 712-717.

[39] Z. Li, V. Yangali Quintanilla, R. Valladares Linares, Q. Li, T. Zhan, and G. Amy, Flux Patterns and Membrane Fouling Propensity during Desalination of Seawater by Forward Osmosis, Water Research, 46 (2011) 195-204, doi:10.1016/j.watres.2011.10.051.

[40] H.B. Park, B.D. Freeman, Z.B. Zhang, J.E. McGrath, Highly chlorine-tolerant polymers for desalination, Angewandte Chemie-International Edition 47 (2008) 6019-6024.

[41] K.C. Ng, H.T. Chua, C.Y. Chung, C.H. Loke, T. Kashiwagi, A. Akisawa, B.B. Saha, Experimental investigation of the silica gel-water adsorption isotherm characteristics. Appl. Thermal Eng. 21 (2001), pp. 1631-1642.

[42] M.A.K. Al-Sofi, A.M. Hassan, G.M. Mustafa, A.G.I. Dalvi, M.N.M. Kither, Nanofiltration as means of Achieving Higher TBT of $\geq 120^{\circ} \mathrm{C}$, Desalination (1998), 123-129.

[43] N. Ghaffour, V.K. Reddy and M. Abu-Arabi, Technology development and application of solar energy in desalination: MEDRC contribution, Renewable and Sustainable Energy Reviews 15 (2011) 4410-4415.

[44] H. Mahmoudi, N. Saphis, M. Goosen, S. Sablani, A. Sabah, N. Ghaffour, N. Drouiche, Assessment of wind energy to power solar brackish water greenhouse desalination units - A case study, Renewable and Sustainable Energy Reviews 13 (2009) 2149-2155.

[45] D. Zejli, A. Ouammi, R. Sacile, H. Dagdougui, A. Elmidaoui, An optimization model for a mechanical vapor compression desalination plant driven by a wind/PV hybrid system, Applied Energy 88 (2011) 4042-4054.

[46] A. Gastli, Y. Charabi, S. Zekri, GIS-based assessment of combined CSP electric power and seawater desalination plant for Duqum-Oman, Renewable and Sustainable Energy Reviews 14 (2010) 821-827.

[47] International Atomic Energy Agency (IAEA), www.iaea.org

[48] G. Leitner, Developer selected for 25 MGD Florida West Coast seawater desalting plant, Desalination and Water Reuse 9 (1999) 11-16.

[49] M. Methnani, DEEP: A tool for evaluating co-generated power and desalination strategies, Desalination 166 (2004) 11-15. 
[50] Jr. Moch, M. Chapman, D. Steward, Development of a CD-ROM cost program for water treatment projects, Membrane Technology (2003) 5-8.

[51] S. Nisan, L. Volpi, Evaluation of desalination costs with DEEP, International Journal of Nuclear Desalination 1 (2004) 298-307.

[52] A. Tua, Tua Engineering Ltd., MEDRC workshop on Practical Aspects of Membrane Desalination: A review of System Design and Operation \& Maintenance (www.medrc.org), Sharm El Sheikh, Egypt, April, 2008, [personal communication].

[53] I. Watson et al., Desalting Handbook for Planners, $3^{\text {rd }}$ editition, US department of the Interior, Bureau of Reclamation Technical Service Center Water Treatment Engineering and Research Group Cooperative Assistance Agreement Number: 98-PG-81-0366, Desalination R\&D program number 72 .

[54] Y. Zhou, R.S.J. Tol, Evaluating the cost of desalination and water transport, Water Resour. Res. 41 (2005), DOI:10.1029/2004WR003749.

[55] M.K. Wittholz, B.K. O’Neill, Estimating the cost of desalination plants using a cost database, Desalination 229 (2008) 10-20.

[56] S. Kawamura, W. McGivney, Cost estimating manual for water treatment facilities, John Wiley \& Sons, 2008.

[57] M.H.I. Dore, Forecasting the economic costs of desalination technology, Desalination 172 (2005) 207-214.

[58] M. Goosen, H. Mahmoudi, N. Ghaffour, Water desalination using geothermal energy, Energies 3 (2010) 1423-1442.

[59] R.B. Saffarini, E.K. Summers, H.A. Arafat, V.J.H. Lienhard, Economic evaluation of stand-alone solar powered membrane distillation systems, Desalination 299 (2012) 55-62.

[60] H. Mahmoudi, N. Saphis, M.F. Goosen, N. Ghaffour, N. Drouiche, A. Ouagued, Application of geothermal energy for heating and fresh water production in a brackish water greenhouse desalination unit: A case study, Renewable and Sustainable Energy Reviews 14 (2010) 512-517.

\section{List of tables}

Table 1: Market historical and forecast of desalination systems [8].

Table 2: Main improvements of thermal processes.

Table 3: Energy consumption and water cost (average values) of large scale commercial desalination processes $[2-4,8,13,14,16,18]$. 
Table 4: Water cost of different recent large scale projects $[2,8]$.

\section{List of figures}

Figure 1: Installed (left) and forecast (right) desalination capacity by technology (as of first quarter of 2012) [2].

Figure 2: Unit water cost trends by SWRO and MSF processes.

Figure 3: Water resources cost trends [12].

Figure 4: Investment costs in RO processes vs. capacity [18].

Figure 5: Diagram of TWC analysis for desalination processes.

Figure 6: Energy consumption in SWRO: (left) one-pass RO, salinity= 35 g/L; (right) 2-pass RO, salinity $=39 \mathrm{~g} / \mathrm{L}$.

Figure 7: Unit water cost breakdown for MSF (left) and RO (right) [33].

Figure 8: TWC of different SWRO plants in operation and contracted (average capacity ' $\mathrm{m}^{3} / \mathrm{d}$ ' and average cost ' $U S \$ / \mathrm{m}^{3}$ ' for each year). 